http://dx.doi.org/10.30681/23588403v11i010617

\title{
O "POLÍTICO” E A SIGNIFICAÇÃO: UMA ANÁLISE EM DICIONÁRIOS
}

Data de recebimento: $25 / 07 / 2017$

Aceite: 05/09/2017

\author{
Jéssica Rabelo NASCIMENTO (UEMS) ${ }^{1}$ \\ Keyla Lima da SILVA (UEMS) ${ }^{2}$ \\ Naiara de Lima MORO (UEMS) ${ }^{3}$
}

\begin{abstract}
Resumo: Neste presente artigo analisaremos a palavra "político" e seus significados. E os sentidos dados à palavra político são influenciados pelas condições de produção que o homem possui no momento da enunciação do termo, e até mesmo pelo contexto histórico em que está inserida na sociedade. Foram utilizados verbetes de dicionários dos últimos quatro séculos, sendo o primeiro de 1728 , o segundo de 1832 , o terceiro de 1986 e o último do ano 2000 . Com esta análise, esperamos repassar o jogo que as palavras pode trazer para quem a enuncia no acontecimento. Esperamos demonstrado a relação da língua com o falante no espaço de enunciação. E alocado os conceitos básicos adquiridos nos estudos da História das Ideias Linguísticas. Onde a palavra político ser analisada em quatro séculos diferente e evidencias e diferença de sentido na enunciação do acontecimento. Os conceitos, definições e entendimentos foram retirados de Eduardo Guimarães, com a teorização da Semântica do Acontecimento.
\end{abstract}

Palavras-chave: Político, Dicionário, Acontecimento, Semântica, Signifficado.

Abstract: In the present article, we will analyze the term "political" and its signification. We must consider the meanings given to the word "political" are influenced by condition of production that man has at the moment of enunciation of the word, and even by the historical context in which the enunciation is inserted in the society. Dictionaries of the last four centuries were used, veing the first from 1728, the second from 1832, the third from 1986 and the last of the year 2000. With this analysis, we expect to pervade the game that words can bring to those who enunciate it in the event, demonstrating the relation between the language and the speaker in the space of enunciation. From the basic concepts acquired in the studies of the History of Linguistic Ideas, the word "political" will be analyzed in four different centuries and we will show the differences of meaning in the enunciation of the event. The concepts, definitions and understandings were taken from Eduardo Guimarães, with the theory of Semantics of the Event. Keywords: Political, Dictionary, Event, Semantics, Signification.

\section{Introdução}

O termo político em diferentes momentos históricos, em diferentes locais do mundo assumiu papeis, isto é, significados, variados. Os sentidos dados à palavra político são

\footnotetext{
${ }^{1}$ Jéssica Rabelo Nascimento - Aluna de Letras Bacharelado- Linguística / UEMS - Universidade Estadual do Mato Grosso do Sul. (jessica nascimento26@live.com)

${ }^{2}$ Keyla Lima da Silva - Aluna de Letras Bacharelado- Linguística / UEMS - Universidade Estadual do Mato Grosso do Sul. (keyla_lim@hotmail.com)

${ }^{3}$ Naiara de Lima Moro - Aluna de Letras Bacharelado- Linguística / UEMS - Universidade Estadual do Mato Grosso do Sul. (naiara.moro@outlook.com)
} 
influenciados pelas condições de produção que o homem possui no momento da enunciação do termo, e até mesmo pelo contexto histórico em que está inserida a sociedade. No presente texto, procuramos analisar quais mudanças ocorreram no verbete político ao decorrer de quatro séculos (XVIII, XIX, XX e XXI), dando, assim, uma diacronia ao estudo.

Etimologicamente, político vem do grego politikos, que significa "cívico". Por sua vez, o termo politikos teve origem a partir da palavra polites ("cidadão"), que se originou de polis ("cidade"). Enquanto política tem sua origem em politika, o plural de politikos (ou "as coisas políticas"). Dessa forma, é perceptível como, desde os tempos mais antigos, o político é elementar à sociedade, sendo algo essencial para uma boa política - ou arte de governar os povos. Por esse motivo, ambas as palavras (político e política) tiveram seus significados detalhados, dando, no entanto, maior ênfase ao termo político.

A partir da etimologia, pode-se ver como o primeiro sentido oferecido ao termo estudado é caracteriza aos que se dedicavam ao governo de alguma região - da polis, tendo como objetivo o bem de todo um povo, e esquecendo se seus interesses pessoais. Entretanto, atualmente é possível verificar a existência de dois sentidos para a palavra político: o primeiro é aquele relacionado a governo, administração; o segundo coloca-se no âmbito de politicagem, isto é, aquele que fez política mesquinha, sórdida.

Por meio dessa comparação, conclui-se que as palavras, ao longo do tempo, vão ter seu significado alterado, ou aumentará a quantidade de significados para um mesmo termo. E, nesse estudo buscamos analisar a palavra político em diferentes séculos e, a partir daí, verificar como seu significado foi relacionado com a sociedade da época.

Segundo Eni Orlandi (2001), o dicionário, que também auxilia na construção das ideias a respeito da língua, é um objeto que passa conhecimento não apenas linguístico, mas histórico e social. Para fins comprovativos dessa ideia, utilizamos nessa análise o VOCABULARIO PORTUGUEZ \& LATINO, aulico, anatomico, architectonico..., datado de 1728; é possível notar, a partir dos verbetes, como vivia a sociedade da época e o contexto histórico em que ela está inserida.

Os dicionários escolhidos para análise foram produzidos em diferentes contextos históricos: o primeiro, de 1728, organizado pelo padre luso-francês Raphael Bluteau, que dedica a obra ao rei D. João V, conhecido por seu grande apreço ao luxo, estava tornando Portugal mais dependente de sua colônia, o Brasil, e fazendo o país perder espaço de como produtor, já que visava o comércio dos bens da colônia. Além disso, em questão temporal, trata-se do período pré-iluminismo, ou seja, período onde estavam aflorando as mudanças em diversas áreas, inclusive na escrita. 
No segundo glossário, de 1832, o Brasil era governado pela Trina Permanente, que, nesse exato ano, sofreu uma tentativa de golpe, por parte do então ministro da justiça Diogo Antônio Feijó. O terceiro dicionário, já do final da segunda metade do século XX (1986), corresponde à época do anúncio do Plano Cruzado, que tinha como principal objetivo o controle da inflação, muito elevada naquele período; a princípio, foi muito bem sucedido, mas passou a ser um fiasco com o passar dos meses; deixou e funcionar ao final do ano. E, finalmente, o quarto e último dicionário, do ano 2000, é marcado pela comemoração de 500 de descobrimento do Brasil.

Com um bônus, a partir dos verbetes colocados no Anexo, é possível ver como a nossa língua evoluiu, e passou a ter características muito particulares, próprias do idioma português. Pode-se perceber, também, as alterações ortográficas que o idioma sofreu ao decorrer desses quatro séculos já citados.

Por fim, tanto o político, quanto a política, dizem respeito a polis, ou a cidade. Isto é, ambos relacionam-se com o ato de governo, de deter o poder, sempre tendo como primeiro plano o bem dos cidadãos, o que, conforme sabemos, não é o que acontece sempre.

\section{A Semântica do Acontecimento}

No desenvolvimento de nossas pesquisas, usaremos a Semântica do Acontecimento, proposta por Eduardo Guimarães no Brasil. As palavras, nessa teoria, ou "expressões linguísticas significam no enunciado pela relação que têm com o acontecimento em que funcionam", com o texto (GUIAMARÃES, 2002, p.5). A enunciação só se dá pelo funcionamento da nossa língua, enquanto o seu acontecimento de linguagem. Nessa enunciação, enquanto acontecimento de linguagem, é que nos possibilita estudar e investigar os sentido da palavra "político" e uma de suas cognatas (política) em alguns dicionários da língua portuguesa. Assim, tomamos o passado não enquanto lembrança, mas enquanto rememoração de enunciação, e na constituição do acontecimento na sua temporalidade e o real na sua materialidade histórica.

Nessa temporalidade do acontecimento enunciativo do dicionário, observamos como a palavra "político" e sua cognata, política, são definidas nos dicionários e compostos por unidades textuais menores: apresentação e etimologias.

A semântica é um dos ramos da linguística que estuda o significado das palavras, textos ou frases de uma língua. Ela se encontra dividida em Descritiva e Sincrônica, sendo a 
que estuda o sentido atual das palavras, e em Histórica ou Diacrônica, que estuda o sentido que as palavras passaram com o tempo e no espaço.

Para entendermos o Acontecimento e Temporalidade aqui colocados pela linha de Guimarães utilizamos os textos de base para a introdução da "Semântica do Acontecimento", publicada em 2005. Fica evidente a relação que o autor elucida com a língua e o falante. E o acontecimento como a origem do tempo na linguagem.

Considero que algo é acontecimento enquanto diferença na sua própria
ordem. E o que caracteriza a diferença é que o acontecimento não é um
fato no tempo. Ou seja, não é um fato novo enquanto distinto de
qualquer outro ocorrido antes do tempo. O que o caracteriza como
diferença é que o acontecimento temporaliza. Ele não está num presente
de um antes e de um depois do tempo. O acontecimento instala sua
própria temporalidade: essa é a diferença (GUIMARÃES, 2005, p. 11).

A busca pelos verbetes propiciou analisar a estrutura, que como um conjunto, oferece marcas da temporalidade, quando observado pela enunciação. Esse conjunto composto pela palavra-entrada e pelas definições é colocado pelo sujeito lexicógrafo com toda propriedade, porém impregnado com memória de sentido e rememoração, no que compromete a interdiscursividade.

O enunciado definidor, assim, é considerado em uma rede de relações parafrásticas com outros enunciados, na qual se estabelecem os limites e as fronteiras das formações discursivas (NUNES, 2006, p. 36).

Identificar nas análises em dicionários a paráfrase, a polissemia, os equívocos é comum, por tratar de repetições de palavras-entradas.

Se os estudos das formações e das heterogeneidades discursivas nos trazem elementos para pensar as continuidades e rupturas do discurso lexicográfico, as noções de repetição e equivoco nos conduzem a refletir sobre as condições desses processos. Só há continuidade e rupturas porque há repetições e equívocos. A repetição pode levar ao mesmo (paráfrase) ou ao diferente (polissemia) (NUNES, 2006, p. 30). 
Usaremos estes conceitos para compreender como o sentido das palavras podem ser parafrásticos ou polissêmicos. Para entender como as palavras se constituíram em suas definições e de que maneira foi exposta pelo sujeito lexicografo, com este inserido em uma sociedade organizada.

\section{Vocabulario portuguez \& latino: aulico, anatomico, architectonico... (1728)}

Após diversas atualizações no dicionário, analisamos o oitavo volume, de dez existentes desse dicionário. Possivelmente pela sua data de publicação, esse glossário é feito em forma dissertativa, com verbos na primeira pessoa do singular, como um texto informativo e pessoal, diferentemente dos dicionários convencionais.

Para início dessa análise, é possível verificar o verbete política é apresentado inicialmente por meio de sua etimologia, sendo polis, relativo à cidade, e itiqui, relacionado à ethica - ou filosofia moral, que serve para instrução e reforma da humanidade. Outra acepção atribuída à palavra política é a de instrução para um bom comando àqueles que detêm o poder, e de ordem, aos que a eles estão submetidos. Além disso, a política está caracterizada como algo que é pertinente aos príncipes, pois eles são os responsáveis pelo governo do mundo terreno, sendo os representantes de Deus na Terra. Completando esse sentido dado à palavra, entende-se que o principal objetivo da política não é o sucesso daquilo que está sendo controlado (seja Estado, cidade, Império, entre outras formas de administração de um espaço), mas sim que sejam cumpridas as leis de Deus.

O poema ${ }^{4}$, crítico-político, de autoria anônima, do ano de 1640 , citado no verbete política, traz alguns lembretes aos príncipes para um bom governo. Em resumo, poema apresenta regras de boa conduta e honestidade dos príncipes para o povo; responsabilidade do governante para com o seu governo; e manter a justiça, que é o caminho para um bom mandato.

A primeira acepção dada à palavra político é “coisa concernente ao governo", isto é, o político é tocante à política e, por consequência, ao governo, à administração de alguma região. Por isso, o "homem político", nesse dicionário, é caracterizado como "aquele que sabe bem as leis da Política", ou seja, que entendam como deve ser feito um bom comando e exercício do poder. E assim, esse homem representa os partidos na composição do governo.

\footnotetext{
${ }^{4} \mathrm{O}$ poema, "Medios fáciles y eficaces para mantenerse una Monarchia en su antiguo esplendor", de escritor anônimo, encontra-se no Anexo desse estudo, juntamente com os verbetes do dicionário de 1728, que estão sendo analisados nesse item.
} 
No dicionário em análise, o termo político também é explicado por meio de um acontecimento histórico: em 1574, na França, os hunos (povo formado por tribos nômades, vindas principalmente da Europa e da Ásia Central), afirmando ser de religião católica, resolveram lutar em prol do povo, visando benefício da população e por um fim aos problemas enfrentados pelo reino francês. Essa interferência dos hunos do reino não tinha nenhuma intenção religiosa. Dessa forma, pelo fato que não agirem com o propósito de "instaurar" uma religião, os hunos foram chamados de políticos. Sendo assim, pode-se concluir que uma das características do político para a época do glossário (1728) é a ausência de interferência religiosa e a busca em agir com neutralidade frente a qualquer assunto que envolvesse a política.

No entanto, posteriormente, esses hunos demonstraram o contrário: aliaram-se ao então rei francês Henrique de Montmorency, para este permanecer no governo de Languedoc, região ao sul da França, rica tanto financeiramente, como culturalmente (com referências na mitologia e a presença de um dialeto próprio).

Desse modo, percebe-se o político em 1728, época em questão, deveria procurar auxiliar a população a partir do cumprimento das leis de Deus, só assim seria um bom político, com uma boa condução de seu poder.

\section{Diccionario da Língua Brasileira (1832)}

Passado um século, a palavra político apresenta significados distintos ao do período anterior analisado. Encontramos como acepções: "concernente à política, que sabe política", "Urbano, civil". Percebemos uma diminuição da preocupação no referente conhecimento do político com as leis. Já não é mais utilizado o advérbio bem para intensificar a posição que o homem que está à frente deve possuir. E observando que duas palavras, urbano e civil, resumem muitos sentidos para não expô-los claramente.

A palavra-entrada política é sucinta ao ser definida, com duas acepções. Encontramos “a arte de governar" e "governo". Estas definições possuem o sentido de ser próprio de quem governa, quando percebesse a restrição criada por uma classe que domina, deixando a entender que só se é político os ligados a função de governar.

Novo dicionário da língua portuguesa - Dicionário (1986) 
Neste dicionário, a palavra político ganha novo sentido, nova forma, novo entendimento. No que diz respeito à organização da sociedade, continua a fiel estratégia mencionada na descrição do dicionário de Antonio de Moraes Silva e vai além, quando o indivíduo político recebe adjetivos bastante prestativos ao considerar-se dessa categoria. As acepções como "1. relativo à, ou próprio da política", "2. relativo aos negócios públicos", "que trata ou se ocupa de política", "3. delicado, polido, cortês", "4. esperto, astuto", "5. estadista", "6. indivíduo político, astuto, esperto". Vimos que o conceito de conhecimentos desaparece, permanecendo com toda a resistência os adjetivos intensificadores, como "astuto e esperto", ou seja, o lugar a ser ocupado por uma pessoa que se diz representante, não consta a preocupações da especialização enquanto dominador das leis e sim de qualidades de gênero desde que este seja desenvolvido.

Na sequência passamos para a palavra-entrada política que constituiu muitas acepções como "1. ciência dos fenômenos referente ao estado; ciência política", "2. sistema de regras respeitantes a direção dos negócios públicos”, “3. arte de bem governar os povos”, "4. conjunto de objetos que informam determinado programa de ação governamental e condicionam a sua execução", "5. princípio doutrinário que caracteriza a estrutura constitucional do estado", "6. posição ideológica a respeito dos fins dos estados”, “7. atividade exercida na disputa dos cargos de governo ou no proselitismo partidário", "8. habilidade no trato das relações humanas, com vista à obtenção dos resultados desejados", "9. civilidade, cortesia”, “10. astúcia, ardil, artifício, esperteza”. Com todas as definições aqui expostas percebemos que de tantas houve a necessidade de enumerá-las, mantendo uma ordem. É evidente ainda uma categoria restrita que utiliza estratégias, tem qualidade apuradas, sendo a definição enumerada sete a que traz um sentido diferente que até agora não havia sido identificado. Levando para um sentido de disputa essa definição é algo bem favorável a época que está inserida, uma vez que as disputas partidárias ocorrem com mais frequência, visualizamos claramente o sujeito afetado por sua história.

\section{Dicionário Aurélio (2000)}

$\mathrm{Na} 4^{\mathrm{a}}$ edição publicada deste dicionário, percebemos a unificação do sentido da palavra-entrada político e sua definição com relação ao dicionário do século XX e este do primeiro ano do século XXI. Traz como acepções "1. da, ou próprio da política”, "2. Que trata ou se ocupa de política”, “3. cortês, polido”, “4. astuto, hábil”, “5. individuo que exerce ou 
procura exercer a política”. Ratificando praticamente as mesmas descrições do politico de 1986, e notadamente a enumeração mostra-se mais uma vez necessária, pela quantidade de definições que a palavra evoca.

Explorando a palavra-entrada política encontramos as muitas acepções como, "1. conjunto dos fenômenos e das práticas relativos ao Estado ou a uma sociedade", "2. arte e ciência de bem governar, de cuidar dos negócios públicos”, “3. qualquer modalidade de exercício da política", "4. habilidade no trato das relações humanas", "5. modo acertado de conduzir uma negociação; estratégia". É notória a reposição do advérbio bem desta vez intensificando as habilidades exigidas para fazer um bom governo. E é atribuída claramente a definição o sentido de estratégia, que até então era interpretação de outras definições.

\section{O termo político: um breve uso na atualidade}

O político teve seu sentido "alterado" na sociedade atual. Esse destaque foi tomado pelo capital, deixando, assim, o Estado de ser o mais importante. Isso acontece devido às ligações diretas que todas as decisões têm com o poder econômico, ou seja, o interesse econômico do Estado, ou até mesmo de uma grande empresa ou governante específico, está acima dos interesses do país. Pode-se perceber, a partir disso, que aquela velha definição do termo político, que sempre visa o bem comum, não se aplica aos dias de hoje.

Os Estados estão dando uma enorme importância às grandes empresas; e os interesses da sociedade, que deveriam ser mais bem observados pelos políticos, acabam sendo ocultados, substituídos pela ambição de uma pessoa ou instituição, que sempre visam o acúmulo de capitais para si mesmo.

Quando decisões, relativas ao povo, porém contrárias à burguesia, são tomadas, este grupo econômico consegue, por meio de suas armas políticas, a mudança ou a sabotagem na decisão, muitas vezes prejudicando a população menos favorecida.

O político, nesse meio e nos tempos atuais, tornou-se um representante do capital. Dessa forma, atualmente, o não se caracteriza pela preocupação com o "bom governo", nem com a prática de uma boa política, como nos séculos anteriores. Isso quer dizer que ele toma decisões com objetivo de beneficiar os empresários - aqueles que possuem grande poder monetário. 
Algumas considerações

Com o progresso desta análise, esperamos ter repassado o jogo que as palavras pode trazer para quem a enuncia no acontecimento. Esperamos ter demonstrado a relação da língua com o falante no espaço de enunciação. E de ter alocado com excelência os conceitos básicos adquiridos nos estudos da Historia das Ideias Linguísticas. A palavra político analisada em quatro séculos diferente evidência também a diferença de sentido na enunciação do acontecimento e ainda como sujeitos que fizeram a reescrituração dessa palavra, considerando a rememoração um tanto aparente no que diz respeito da língua portuguesa.

\section{REFERÊNCIAS BIBLIOGRÁFICAS}

ALCALÁ-ZAMORA, José N. Felipe IV: El hombre y el reinado. Madrid: RAH, 2005.

GUIMARÃES, Eduardo. Semântica do Acontecimento: um estudo enunciativo da designação. 2. Ed. Campinas, SP: Pontes, 2002.

. Texto e argumentação: um estudo de conjunções do português. 3. Ed. Campinas, SP:

Pontes, 2002.

NUNES, Jose Horta. Dicionários no Brasil: análise e história. Campinas, SP: Pontes Editores

- São Paulo, SP: Fapesp - São José do Rio Preto, SP: Faperp, 2006.

ORLANDI, Eni Puccinelli (Org.). Apresentação. In. História das ideias linguísticas: construção do saber metalinguístico e constituição da língua nacional. Campinas - SP: Pontes; Cáceres, MT: Unemat Editora, 2001.

DICIONÁRIO ETIMOLÓGICO. Origem da palavra Político. Disponível em: <http://www.dicionarioetimologico.com.br/politico/>. Acesso em: 05 nov 2015.

\section{REFERÊNCIAS DOS DICIONÁRIOS}

BLUTEAU, Raphael. Vocabulario portuguez \& latino: aulico, anatomico, architectonico... Coimbra: Collegio das Artes da Companhia de Jesu, 1712 - 1728. 8 v.

PINTO, Luiz Maria da Silva. Diccionario da Lingua Brasileira. Ouro Preto, 1832. 
FERREIRA, Aurélio Buarque de Holanda. Novo dicionário da língua portuguesa. 2.ed. Rio de Janeiro: Nova Fronteira, 1986.

FERREIRA, Aurélio Buarque de Holanda. Mini Aurélio. 4.ed Rio de Janeiro: Nova Fronteira, 2000.

\section{ANEXO}

VOCABULARIO PORTUGUEZ \& LATINO: aulico, anatomico, architectonico ... (1728)

Política: He palavra composta de Polis, que em Grego val o mesmo que Cidade, \& Itiqui, que responde ao que chamamos Ethica, ou Filosofia moral, que se emprega na moderação das payxões, \& composição dos costumes. E assim na sua mais ampla significação, Politica, he a que às Cidades, Republicas, Reynos, \& Imperios dá preceytos do bom governo, assim para o bem dos que mandão, como dos que obedecem. Esta he propriamente a sciencia dos Principes, que são os substitutos de Deos no governo do mundo. O fim principal da boa Poitica não he a prosperidade temporal dos Estados, mas a gloria de Deos, na administração da justiça, \& observância das suas leys. Politica. A sciencia de governar hum Estado, huma Republica; \& Algüns anos há, que me veyo às mãos hum Soneto Castelhano com as principaes advertências politicas, necessárias a hum Principe para o bom governo, \& prosperidade de seus Estados. Com o prelo levará mais publico, que com andar escrito de mão.

Cobrar, y administrar con buena cuenta.

No dar a quien por si no lo merece.

No quitar lo que al otro pertenece.

No permitir que el premio pare en venta.

Pagar las deudas, que el descuido aumenta.

$Y$ moderar el gasto, que empobrece,

Tener en el, que más justo parece,

Providencia prudente, y no avarienta.

Socorrer las fronteras fin tardança,

Mantener en su honor a la Milicia

Fomentar del comercio la ordenança.

Formar Artes fabriles con pericia,

Alentar las virtudes, y labrança,

$Y$ sobre tudo administras justicia. 
A Politica de Platão. Os livros que Platão esreveo sobre a Politica. Platonus politia, ae. Fem. Cic.

Político: Cousa concernente ao governo. Politicus, a, um. Cic.

Homem Politico, que sabe bem as leys da Politica.

Hum Politico. Aquelle que sabe accomodarse ao tempo.

Politica dispensação, chamão os Jurisconsultos à que respeyta o bem de toda huma Communidade. Politica dispensatio, onis. Fem.

Politica Bemaventurança, chamão os Theologos à que logra o homem, não no seu particular, como pessoa privada, mas no trato comum da gente como ministro publico. Vid.

Politicos. Em Fraça no anno de 1574. Huns Cathoicos mal contentes, tomarão as armas, protestando que seu fim era só aliviar o povo, acodir ao bem comum, \& remediar as desordens do Reyno, sem se meterem em negocio algum concernete à Religião. Estes taes forão chamados Politicos, porque com politica neutralidade nem favorecião, nem encontravão os Hereges; porém chegado o tempo de se declararem, tirarão estes Politicos a mascara, \& seguirão o partido de Henrique de Monmorency, que contra a liga dos Catholicos se queria conservar no governo do Languedoc.

\section{Diccionario da Lingua Brasileira (1832)}

Política: $s . f$. Arte de governar. Governo. Policia.

Político: adj. Concernente à politica, que sabe politica. Urbano, civil.

\section{Novo dicionário da língua portuguesa - DICIONÁRIO (1986)}

Política: [Fem. Substantivado de político] 1. Ciência dos fenômenos referentes ao Estado; ciência política. 2. Sistema de regras respeitantes à direção dos negócios públicos. 3. Arte de bem governar os povos. 4. Conjunto de objetivos que enformam determinado programa de ação governamental e condicionam a sua execução. 5. Princípio doutrinário que caracteriza a estrutura constitucional do Estado. 6. Posição ideológica a respeito dos fins do Estado. 7. Atividade exercida na disputa dos cargos de governo ou no proselitismo partidário. 8. Habilidade no trato das relações humanas, com vista à obtenção dos resultados desejados. 9. $P$. ext. Civilidade, cortesia. 10. Fig. Astúcia, ardil, artifício, esperteza.

Político: [Do gr. Politikós, pelo lat. Politicu] 1. Relativo à, ou próprio da política. 2. Relativo aos negócios públicos. 3. Que trata ou se ocupa de política. 4. Delicado, polido, cortês. 5. Fig. Esperto, astuto. 6. Aquele que trata ou se ocupa de política; estadista. 7. Fig. Indivíduo político, astuto, esperto. 


\section{Mini Aurélio: o minidicionário da língua portuguesa - DICIONÁRIO (2000)}

Política: $s f$. 1. Conjunto dos fenômenos e das práticas relativos ao Estado ou a uma sociedade. 2. Arte e ciência de bem governar, de cuidar dos negócios públicos. 3. Qualquer modalidade de exercício da política (2). 4. Habilidade no trato das relações humanas. 5. Modo acertado de conduzir uma negociação; estratégia.

Político: adj. 1. Da, ou próprio da política. 2. Que trata ou se ocupa de política. 3. Cortês, polido. 4. Astuto, hábil. *sm 5. Indivíduo que exerce ou procura exercer a política (2). 